\title{
Carotid thickness and atherosclerotic plaque stability, serum inflammation, serum MMP-2 and MMP-9 were associated with acute cerebral infarction
}

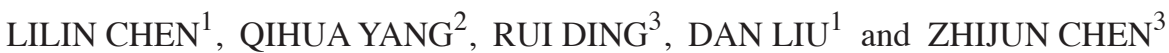 \\ ${ }^{1}$ Stroke Office, Departments of ${ }^{2}$ Ultrasound Imaging and ${ }^{3}$ Neurosurgery, \\ Jingmen First People's Hospital, Jingmen, Hubei 448000, P.R. China
}

Received April 9, 2018; Accepted October 9, 2018

DOI: $10.3892 /$ etm.2018.6868

\begin{abstract}
Correlations of carotid intima-media thickness (IMT), atherosclerotic plaque stability, serum inflammatory factors and serum matrix metalloproteinase (MMP)-2 and MMP-9 levels with the condition of disease in patients with acute cerebral infarction were analyzed to explore the predictive value of these risk factors. A total of 56 patients diagnosed with acute cerebral infarction in Jingmen First People's Hospital from February 2016 to January 2017 were selected and divided into the plaque stability group $(n=25)$ and plaque instability group $(n=31)$. Our results showed that the level of total cholesterol (TC) in the plaque instability group was significantly higher than that in the plaque stability group $(\mathrm{P}<0.05)$. IMT and National Institutes of Health Stroke Scale (NIHSS) score in the plaque instability group were significantly higher than those in the plaque stability group, but eccentricity index (EI) and Barthel index were significantly lower than those in the plaque stability group $(\mathrm{P}<0.05)$. The serum $\mathrm{C}$-reactive protein $(\mathrm{CRP})$, tumor necrosis factor- $\alpha$ (TNF- $\alpha$ ) and interleukin-6 (IL-6) levels in the plaque instability group were significantly higher than those in the plaque stability group $(\mathrm{P}<0.05)$. The levels of serum MMP-2 and MMP-9 in the plaque instability group were significantly higher than those in the plaque stability group $(\mathrm{P}<0.05)$. Barthel index was correlated with IMT $(r=-0.693, \mathrm{P}<0.01)$, MMP-2 (r=-0.605, P<0.01), CRP $(r=-0.765, \mathrm{P}<0.01)$ and EI $(\mathrm{r}=0.811, \mathrm{P}<0.01)$, respectively. Hemoglobin A1c (HbA1c), TC, systolic blood pressure, coronary heart disease, diabetes mellitus, IMT, EI, CRP, TNF- $\alpha$, IL-6, MMP-2 and MMP-9 had independent predictive values for acute cerebral infarction $(\mathrm{P}<0.05)$. Carotid IMT, stability of the atherosclerotic
\end{abstract}

Correspondence to: Dr Qihua Yang, Department of Ultrasound Imaging, Jingmen First People's Hospital, 168 Xiangshan Avenue, Dao, Jingmen, Hubei 448000, P.R. China

E-mail: eyplk439@163.com

Key words: carotid intima-media thickness, atherosclerosis, inflammatory factors, matrix metalloproteinase- 9 plaque, serum inflammation, serum MMP-2 and MMP-9 levels have close correlations with acute cerebral infarction. The larger the carotid IMT is, the more unstable the plaque is and the higher the levels of serum inflammatory factors, MMP-2 and MMP-9 are, the greater the risk of acute cerebral infarction will be.

\section{Introduction}

Acute cerebral infarction is a common disease in clinical practice, especially in neurology, which frequently occurs in elderly patients and has higher disability fatality rates (1). With the gradual aggravation of social aging, the incidence rates of cardiovascular and cerebrovascular diseases are also increased. Acute cerebral infarction is also known as cerebral ischemic stroke, under which brain cells are unable to have normal blood circulation, and varying degrees of ischemia and anoxia lead to malacia or necrosis of brain tissue cells, resulting in disability or death of patients, and greatly reducing the quality of life of patients (2).

Previous data have shown that carotid artery stenosis is the main factor among various factors that cause ischemic encephalopathy, but with the continuous strengthening of evidence-based basis, it has been found that rupture and erosion caused by the instability of atherosclerotic plaque also play important roles in promoting the occurrence of acute cerebral infarction $(3,4)$. On the other hand, overexpressed inflammatory cytokines play an important role in the occurrence and development of patients with acute cerebral infarction. The most common inflammatory cytokines are C-reactive protein (CRP), tumor necrosis factor- $\alpha$ (TNF- $\alpha$ ) and interleukin-6 (IL-6), which significantly affect the pathophysiological processes of acute cerebral infarction brain cells at the same time $(5,6)$. Inflammatory cytokines are closely related to the occurrence and the severity of acute cerebral infarction. Matrix metalloproteinase (MMP) is a substance synthesized and secreted by macrophages (7). MMP-2 and MMP-9 are members of various substances decomposed by it, and the main roles are to degrade collagen fibers, elastic fibers and other extracellular matrixes, resulting in weakened fibrous cap function and unstable carotid plaque, thereby increasing the risk of acute cerebral infarction (8). 
Therefore, the study on the correlations of carotid artery thickness, atherosclerotic plaque stability, serum inflammatory factors and MMP with acute cerebral infarction has an important reference value in clinical diagnosis and prognosis.

\section{Patients and methods}

General data. A total of 56 patients diagnosed with acute cerebral infarction in Jingmen First People's Hospital (Jingmen, China) from February 2016 to January 2017 were selected and divided into the plaque stability group $(\mathrm{n}=25)$ and plaque instability group $(\mathrm{n}=31)$ based on the stability of plaque indicated in color ultrasonography. Among them, there were 36 males and 20 females aged 62-91 years, with an average age of $79.34 \pm 4.82$ years. Diagnostic criteria for all enrolled patients were based on revised standards of Chinese Fourth Conference on Cerebrovascular Disease in combination with brain computed tomography (CT) or magnetic resonance imaging. Inclusion criteria: patients who had complete clinical data and signed the informed consent; patients who were diagnosed with acute cerebral infarction. Exclusion criteria: cerebral embolism patients with determined source of emboli, such as atrial fibrillation and peripheral vascular disease, patients with coma, disturbance of consciousness or disability due to other causes, for example, drug, malignancy, trauma and arteritis.

This study was approved by the Ethics Committee of Jingmen First People's Hospital. Signed informed consents were obtained from the patients or guardians.

Methods. General data of patients, including age, sex, height, weight, blood pressure, smoking history, and with or without coronary heart disease and diabetes mellitus, were collected. Biochemical and inflammatory indexes of selected patients were measured. National Institutes of Health Stroke Scale (NIHSS) score and Barthel index were calculated.

Determination of biochemical indicators: fasting peripheral blood $(10 \mathrm{ml})$ was drawn from all included patients after fasting for solids and liquids for $10 \mathrm{~h}$ overnight, and the upper serum was used to determine biochemical indicators, including glycosylated hemoglobin Alc (HbAlc) measured through a glycosylated hemoglobin analyzer, and total cholesterol (TC), triglyceride (TG), low-density lipoprotein cholesterol (LDL-C) and high-density lipoprotein cholesterol (HDL-C) measured by an automatic biochemical analyzer provided by Hitachi, Ltd. (Tokyo, Japan).

Measurement of serum inflammatory cytokines, MMP-2 and MMP-9: the enrolled patients did not eat or drink for $10 \mathrm{~h}$ overnight, $10 \mathrm{ml}$ peripheral blood was drawn, and the serum was collected. Serum inflammatory cytokines were measured by immunoturbidimetry, and serum MMP-2 and MMP-9 levels were detected using enzyme-linked immunosorbent assay. Reagents and instruments were provided by Shandong Biological Instrument Co. (Qingdao, China).

Evaluation of carotid artery: carotid intima-media thickness (IMT): carotid ultrasound examination was performed using the Philips iE33 color Doppler ultrasound equipment. The specific sites of the examination were bilateral common carotid artery, bifurcation of common carotid artery and internal carotid artery outside the brain. Each site was measured 3 times, and the average was used as result. Determination of plaque
Table I. Comparison of general data between the plaque stability and instability groups.

\begin{tabular}{|c|c|c|c|}
\hline General data & $\begin{array}{l}\text { Plaque stability } \\
\text { group }(n=25)\end{array}$ & $\begin{array}{l}\text { Plaque instability } \\
\text { group }(n=31)\end{array}$ & P-value \\
\hline Age (years) & $79.53 \pm 5.08$ & $81.07 \pm 4.76$ & 0.312 \\
\hline Sex (male/female) & $16 / 9$ & $20 / 11$ & 0.465 \\
\hline BMI $\left(\mathrm{kg} / \mathrm{m}^{2}\right)$ & $24.23 \pm 1.87$ & $24.96 \pm 1.93$ & 0.766 \\
\hline HbA1c $(\%)$ & $6.08 \pm 2.60$ & $6.12 \pm 3.08$ & 0.724 \\
\hline $\mathrm{TG}(\mathrm{mmol} / \mathrm{l})$ & $1.27 \pm 0.38$ & $1.25 \pm 0.29$ & 0.376 \\
\hline $\mathrm{TC}(\mathrm{mmol} / \mathrm{l})$ & $2.99 \pm 0.92$ & $4.34 \pm 0.88$ & 0.028 \\
\hline HDL-C (mmol/l) & $1.09 \pm 0.41$ & $1.04 \pm 0.25$ & 0.065 \\
\hline LDL-C(mmol/1) & $2.88 \pm 1.23$ & $2.45 \pm 1.01$ & 0.051 \\
\hline $\begin{array}{l}\text { Systolic pressure } \\
(\mathrm{mmHg})\end{array}$ & $145.37 \pm 22.12$ & $150.16 \pm 20.39$ & 0.072 \\
\hline $\begin{array}{l}\text { Diastolic pressure } \\
(\mathrm{mmHg})\end{array}$ & $82.53 \pm 15.13$ & $85.19 \pm 17.68$ & 0.142 \\
\hline $\begin{array}{l}\text { Coronary heart } \\
\text { disease }[\mathrm{n}(\%)]\end{array}$ & $14(56.0)$ & $19(61.3)$ & 0.595 \\
\hline $\begin{array}{l}\text { Diabetes mellitus } \\
{[\mathrm{n}(\%)]}\end{array}$ & $10(40.0)$ & 13 (41.9) & 1.001 \\
\hline $\begin{array}{l}\text { Smoking history } \\
{[\mathrm{n}(\%)]}\end{array}$ & $5(20.0)$ & $8(25.8)$ & 0.119 \\
\hline
\end{tabular}

$\chi^{2}$ test was used to compare coronary heart disease [n (\%)]; diabetes mellitus $[\mathrm{n}(\%)]$ and smoking history $[\mathrm{n}(\%)]$ between the two groups. BMI, body mass index; HbA1c, hemoglobin A1c; TG, triglyceride; TC, total cholesterol; HDL-C, high-density lipoprotein cholesterol; LDL-C, low-density lipoprotein cholesterol.

stability: the stability of the plaque was determined according to the nature of echo displayed in the results of ultrasound examination: high-level echo, stable plaque; low-level or equal echo, unstable plaque; determination of eccentricity index (EI), total thickness of the plaque/measured IMT.

Statistical analysis. Statistical Product and Service Solutions (SPSS) 19.0 software (IBM Corp., Armonk, NY, USA) was used for data processing. Collected data were expressed as mean \pm SD. The $\chi^{2}$ test was used to compare enumeration data. Correlation analysis was carried out over two factors. Logistic regression analysis was performed on relevant risk factors. $\mathrm{P}<0.05$ indicates that the difference was statistically significant.

\section{Results}

Comparison of general data between plaque stability and instability groups. There were no statistical differences in age, sex, body mass index (BMI), HbA1c, TG, HDL-C, LDL-C, systolic pressure, diastolic pressure, coronary heart disease, diabetes mellitus and smoking history between the plaque stability and instability groups $(\mathrm{P}>0.05)$, but the level of TC in the plaque instability group was significantly higher than that in the plaque stability group $(\mathrm{P}<0.05)$ (Table I).

Comparison of IMT, EI, NIHSS score and Barthel index between plaque stability and instability groups. Plaque 
Table II. Comparison of IMT, EI, NIHSS score and Barthel index between the plaque stability and instability groups.

\begin{tabular}{lccc}
\hline Projects & $\begin{array}{c}\text { Plaque stability } \\
\text { group }(\mathrm{n}=25)\end{array}$ & $\begin{array}{c}\text { Plaque instability } \\
\text { group }(\mathrm{n}=31)\end{array}$ & P-value \\
\hline IMT $(\mathrm{cm})$ & $0.205 \pm 0.103$ & $0.341 \pm 0.127$ & 0.001 \\
EI & $0.57 \pm 0.14$ & $0.38 \pm 0.11$ & 0.001 \\
Barthel index & $69.30 \pm 19.4$ & $60.62 \pm 19.3$ & 0.001 \\
NIHSS score & $3.9 \pm 2.8$ & $6.2 \pm 3.1$ & 0.001 \\
\hline
\end{tabular}

IMT, intima-media thickness; EI, eccentricity index; NIHSS, National Institutes of Health Stroke Scale.

Table III. Comparison of serum inflammatory factor levels between the plaque stability and instability groups.

\begin{tabular}{lccc}
\hline $\begin{array}{l}\text { Inflammatory } \\
\text { factors }\end{array}$ & $\begin{array}{c}\text { Plaque stability } \\
\text { group }(\mathrm{n}=25)\end{array}$ & $\begin{array}{c}\text { Plaque instability } \\
\text { group }(\mathrm{n}=31)\end{array}$ & P-value \\
\hline CRP $(\mathrm{mg} / \mathrm{l})$ & $2.39 \pm 0.99$ & $5.48 \pm 1.43$ & 0.001 \\
TNF- $\alpha(\mathrm{ng} / \mathrm{ml})$ & $6.46 \pm 1.09$ & $10.23 \pm 1.19$ & 0.001 \\
$\mathrm{IL}-6(\mu \mathrm{g} / \mathrm{l})$ & $7.21 \pm 1.17$ & $9.24 \pm 1.66$ & 0.001 \\
\hline
\end{tabular}

CRP, C-reactive protein; TNF- $\alpha$, tumor necrosis factor- $\alpha$; IL-6, interleukin-6.

Table IV. Comparison of serum MMP-2 and MMP-9 levels between the plaque stability and instability groups.

\begin{tabular}{lccc}
\hline MMP & $\begin{array}{c}\text { Plaque stability } \\
\text { group }(\mathrm{n}=25)\end{array}$ & $\begin{array}{c}\text { Plaque instability } \\
\text { group (n=31) }\end{array}$ & P-value \\
\hline MMP-2 (ng/ml) & $63.21 \pm 0.56$ & $71.38 \pm 0.45$ & 0.001 \\
MMP-9 (ng/ml) & $301.74 \pm 31.19$ & $356.92 \pm 30.46$ & 0.001 \\
\hline
\end{tabular}

MMP, matrix metalloproteinase.

instability group had obviously increased IMT and NIHSS scores and clearly reduced EI and Barthel index in comparison with the plaque stability group, and the differences were statistically significant $(\mathrm{P}<0.05)$ (Table II).

Comparison of serum inflammatory factor levels between plaque stability and instability groups. Serum CRP, TNF- $\alpha$ and IL-6 levels in the plaque instability group were overtly higher than those in the plaque stability group, with statistically significant differences $(\mathrm{P}<0.05)$ (Table III).

Comparison of serum MMP-2 and MMP-9 levels between plaque stability and instability groups. Serum MMP-2 and MMP-9 levels were evidently elevated in the plaque instability group compared with those in the plaque stability group, and the differences were statistically significant $(\mathrm{P}<0.05)$ (Table IV).

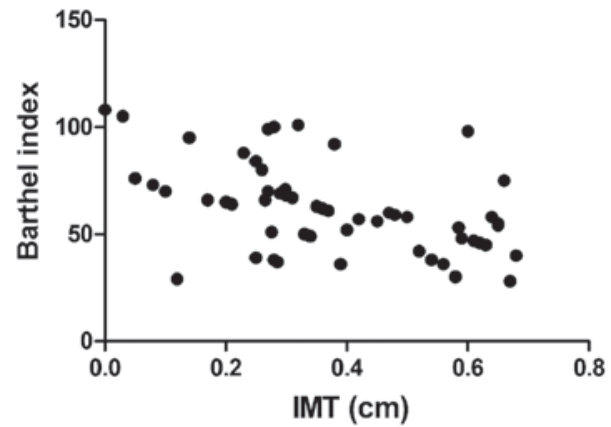

Figure 1. Correlation between IMT and Barthel index. IMT, intima-media thickness.

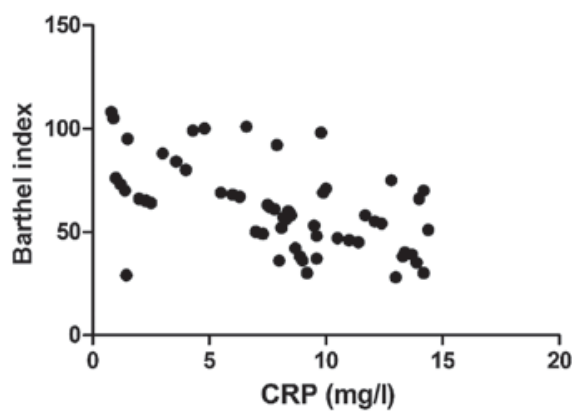

Figure 2. Correlation between CRP and Barthel index. CRP, C-reactive protein.

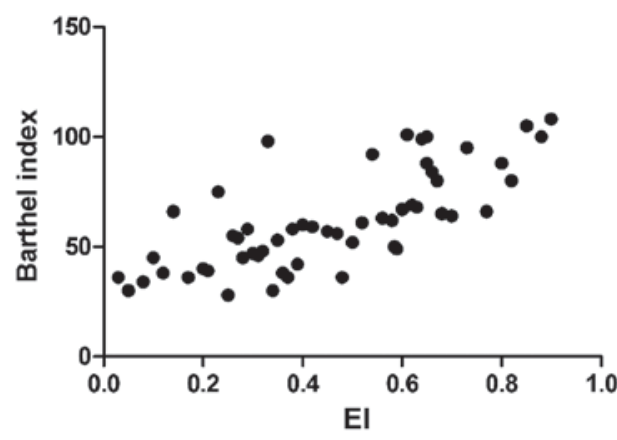

Figure 3. Correlation between EI and Barthel index. EI, eccentricity index.

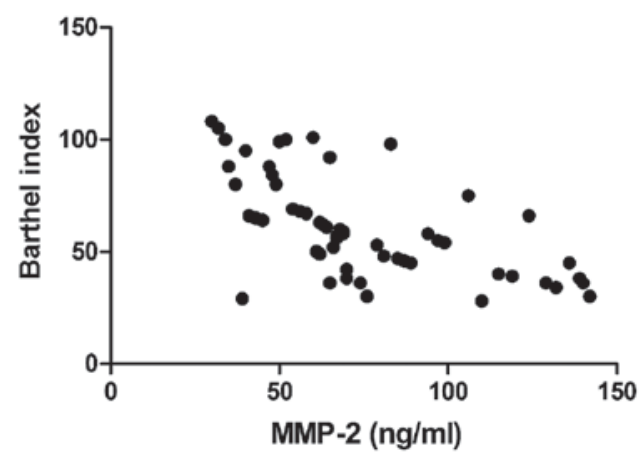

Figure 4. Relationship between MMP-2 and Barthel index. MMP, matrix metalloproteinase.

Correlation analyses of IMT, EI, serum inflammatory factors and MMP-2 with Barthel index. Barthel index was negatively correlated with IMT $(r=-0.693, \mathrm{P}<0.01), \mathrm{CRP}(\mathrm{r}=-0.765$, 
Table V. Logistic regression analyses on the prediction of risk factors for acute cerebral infarction.

\begin{tabular}{lccl}
\hline Factors & P-value & OR & \multicolumn{1}{c}{$95 \%$ CI } \\
\hline Age & 0.108 & 1.094 & $0.957-1.149$ \\
Sex & 0.779 & 0.852 & $0.993-5.979$ \\
BMI & 0.851 & 0.069 & $0.443-18.305$ \\
HbA1c & 0.032 & 1.006 & $0.929-1.113$ \\
TG & 0.527 & 1.447 & $0.465-4.491$ \\
TC & 0.024 & 1.396 & $0.576-3.572$ \\
HDL-C & 0.322 & 0.989 & $0.991-5.035$ \\
LDL-C & 0.961 & 0.082 & $0.445-20.307$ \\
Systolic pressure & 0.013 & 7.543 & $1.918-8.147$ \\
Diastolic pressure & 0.051 & 1.408 & $0.569-4.018$ \\
Coronary heart disease & 0.042 & 1.279 & $0.472-3.961$ \\
Diabetes mellitus & 0.037 & 1.162 & $0.620-4.083$ \\
Smoking history & 0.059 & 1.477 & $0.625-4.199$ \\
IMT & 0.017 & 8.053 & $1.814-9.525$ \\
EI & 0.035 & 1.274 & $0.631-3.929$ \\
CRP & 0.028 & 1.053 & $0.985-1.064$ \\
IL-6 & 0.026 & 1.029 & $0.974-1.081$ \\
TNF- $\alpha$ & 0.005 & 7.349 & $1.918-20.143$ \\
MMP-2 & 0.019 & 1.045 & $0.997-1.323$ \\
MMP-9 & 0.047 & 1.118 & $0.493-5.017$ \\
\hline
\end{tabular}

BMI, body mass index; HbA1c, hemoglobin A1c; TG, triglyceride; $\mathrm{TC}$, total cholesterol; HDL-C, high-density lipoprotein cholesterol; LDL-C, low-density lipoprotein cholesterol; IMT, intima-media thickness; EI, eccentricity index; CRP, C-reactive protein; IL-6, interleukin-6; TNF- $\alpha$, tumor necrosis factor- $\alpha$; MMP, matrix metalloproteinase.

$\mathrm{P}<0.01)$, and MMP-2 $(\mathrm{r}=-0.605, \mathrm{P}<0.01)$, but positively associated with EI $(\mathrm{r}=0.811, \mathrm{P}<0.01)$ (Figs. 1-4).

Logistic regression analyses on the prediction of risk factors for acute cerebral infarction. HbA1c, TC, systolic pressure, coronary heart disease, diabetes mellitus, IMT, EI, serum inflammatory cytokines (CRP, TNF- $\alpha$ and IL-6), MMP-2 and MMP-9 had independent prognostic values for acute cerebral infarction, with statistical significance $(\mathrm{P}<0.05)($ Table $\mathrm{V})$.

\section{Discussion}

Clinically, diseases with the highest morbidity and mortality rates are cardiovascular and cerebrovascular diseases, of which acute cerebral infarction is the most common disease among cerebrovascular diseases (9). The pathogenesis of acute cerebral infarction is based on arterial diseases in and outside the brain. The common arterial diseases include carotid artery stenosis or obstruction caused by the formation of carotid atherosclerotic plaques, plaque rupture and erosion (10). Among many risk factors of acute cerebral infarction, carotid lesions, especially plaque formation, plaque thickness, stability and other properties are the most common and important risk factors (11). Studies have shown that plaque instability increases the onset risk of acute cerebral infarction, and plaque instability is caused by factors such as fibrous cap thickness and fixation degree. Among various conditions determining the stability of the plaque, $\mathrm{EI}$ is also an important indicator in addition to echo and degree of surface smoothness. The lower the EI, the more unstable the plaque $(12,13)$. NIHSS score and Barthel index are generally used to judge the neurologic status in patients with acute cerebral infarction. A higher NIHSS score and a lower Barthel index indicate more severe neurologic impairment (14). In this study, it was found that IMT and NIHSS scores in the plaque instability group were significantly higher than those in the plaque stability group, while EI and Barthel index in the plaque instability group were significantly lower than those in the plaque stability group, and the differences were statistically significant $(\mathrm{P}<0.05)$. In addition, correlation analyses revealed that IMT and Barthel index were negatively correlated, while EI and Barthel index were positively related, suggesting that the thicker the carotid artery thickness is, and the more unstable the plaque is, the more serious the condition of acute cerebral infarction will be.

With continuous and in-depth studies on the pathogenesis of acute cerebral infarction, it has been found that in the early stage of acute cerebral infarction, over-reaction of the inflammatory system in ischemic and infarct regions is also an important factor promoting its development (15). In the process leading to over-reaction of the inflammatory system, neutrophils, macrophages and lymphocytes play a key role, and the excessive synthesis and release of inflammatory cytokines released by the above cells such as interleukin and CRP further lead to inflammatory cascade, increasing the trauma of brain histiocyte $(16,17)$. In addition, blood-brain barrier is damaged in the over-reaction process of the inflammation system, resulting in increased levels of inflammatory cytokines and MMP expression (18). MMP-2 and MMP-9 are important components of MMP. In patients with acute cerebral infarction, increased activity of MMP causes edema in brain histiocytes, and measurement of MMP content can be used to determine the severity of acute cerebral infarction $(19,20)$. The relationship between inflammatory cytokines and acute cerebral infarction was investigated in this study, and it was found that the levels of serum inflammatory cytokines in the plaque instability group were distinctly higher than those in the plaque stability group, and the differences were statistically significant $(\mathrm{P}<0.05)$. Both $\mathrm{CRP}$ and MMP-2 had a negative correlation with Barthel index. Meanwhile, IMT, EI, serum inflammatory cytokines (CRP, TNF- $\alpha$ and IL-6), MMP-2 and MMP-9 had independent predictive values for acute cerebral infarction.

In conclusion, examining carotid artery thickness, atherosclerotic plaque stability, and levels of serum inflammatory factors, MMP-2 and MMP-9 has important significance in judging the severity of acute cerebral infarction and guiding its treatment and prognosis. Risk factors of acute cerebral infarction should be deeply understood, so as to prevent or timely and correctly treat the disease.

\section{Acknowledgements}

This study was supported by the Key Science and Technology Project of Jingmen, Hubei (no. YFZD2016045). 


\section{Funding}

No funding was received.

\section{Availability of data and materials}

All data generated or analyzed during this study are included in this published article.

\section{Authors' contributions}

LC and QY designed the study and performed the experiments. LC, RD and DL collected the data. QY and ZC analyzed the data. LC and QY prepared the manuscript. All authors read and approved the final manuscript.

\section{Ethics approval and consent to participate}

This study was approved by the Ethics Committee of Jingmen First People's Hospital (Jingmen, China). Signed informed consents were obtained from the patients or guardians.

\section{Patients consent for publication}

Not applicable.

\section{Competing interests}

The authors declare no competing interests.

\section{References}

1. Kim HM, Shin HY, Jeong HJ, An HJ, Kim NS, Chae HJ, Kim HR, Song HJ, Kim KY, Baek SH, et al: Reduced IL-2 but elevated IL-4, IL-6, and IgE serum levels in patients with cerebral infarction during the acute stage. J Mol Neurosci 14: 191-196, 2000

2. Dziedzic T: Clinical significance of acute phase reaction in stroke patients. Front Biosci 13: 2922-2927, 2008.

3. Liapis CD, Kakisis JD and Kostakis AG: Carotid stenosis: Factors affecting symptomatology. Stroke 32: 2782-2786, 2001.

4. Ma LL, Song L, Yu XD, Yu TX, Liang H and Qiu JX: The clinical study on the treatment for acute cerebral infarction by intra-arterial thrombolysis combined with mild hypothermia. Eur Rev Med Pharmacol Sci 21: 1999-2006, 2017.

5. Segers D, Helderman F, Cheng C, van Damme LC, Tempel D, Boersma E, Serruys PW, de Crom R, van der Steen AF, Holvoet $\mathrm{P}$, et al: Gelatinolytic activity in atherosclerotic plaques is highly localized and is associated with both macrophages and smooth muscle cells in vivo. Circulation 115: 609-616, 2007.

6. Moreno PR, Purushothaman KR, Fuster V, Echeverri D, Truszczynska H, Sharma SK, Badimon JJ and O'Connor WN: Plaque neovascularization is increased in ruptured atherosclerotic lesions of human aorta: Implications for plaque vulnerability. Circulation 110: 2032-2038, 2004.
7. Casas JP, Shah T, Hingorani AD, Danesh J and Pepys MB: $\mathrm{C}$-reactive protein and coronary heart disease: A critical review. J Intern Med 264: 295-314, 2008.

8. Doyle B and Caplice N: Plaque neovascularization and antiangiogenic therapy for atherosclerosis. J Am Coll Cardiol 49: 2073-2080, 2007.

9. Yang N, Lin M, Wang BG, Zeng WY, He YF, Peng HY, Zeng J, Wu ZY and Zhong Y: Low level of low-density lipoprotein cholesterol is related with increased hemorrhagic transformation after acute ischemic cerebral infarction. Eur Rev Med Pharmacol Sci 20: 673-678, 2016.

10. Bazan HA, Smith TA, Donovan MJ and Sternbergh WC III: Future management of carotid stenosis: Role of urgent carotid interventions in the acutely symptomatic carotid patient and best medical therapy for asymptomatic carotid disease. Ochsner J 14: 608-615, 2014.

11. Bauzá A, Mooibroek TJ and Frontera A: Corrigendum: The bright future of unconventional $\sigma / \pi$-hole interactions. Chemphyschem 16 : 3130, 2015.

12. Hermus L, Tielliu IF, Wallis de Vries BM, van den Dungen JJ and Zeebregts CJ: Imaging the vulnerable carotid artery plaque. Acta Chir Belg 110: 159-164, 2010.

13. Tuttolomondo A, Di Raimondo D, Pecoraro R, Arnao V, Pinto A and Licata G: Atherosclerosis as an inflammatory disease. Curr Pharm Des 18: 4266-4288, 2012.

14. Azzurri A, Sow OY, Amedei A, Bah B, Diallo S, Peri G, Benagiano M, D'Elios MM, Mantovani A and Del Prete G: IFN-gamma-inducible protein 10 and pentraxin 3 plasma levels are tools for monitoring inflammation and disease activity in Mycobacterium tuberculosis infection. Microbes Infect 7: 1-8, 2005.

15. Mairuhu AT, Peri G, Setiati TE, Hack CE, Koraka P, Soemantri A, Osterhaus AD, Brandjes DP, van der Meer JW, Mantovani A, et al: Elevated plasma levels of the long pentraxin, pentraxin 3, in severe dengue virus infections. J Med Virol 76: 547-552, 2005.

16. Muller B, Peri G, Doni A, Torri V, Landmann R, Bottazzi B and Mantovani A: Circulating levels of the long pentraxin PTX3 correlate with severity of infection in critically ill patients. Crit Care Med 29: 1404-1407, 2001.

17. Sprong T, Peri G, Neeleman C, Mantovani A, Signorini S, van der Meer JW and van Deuren M: Pentraxin 3 and C-reactive protein in severe meningococcal disease. Shock 31: 28-32, 2009.

18. Bevelacqua V, Libra M, Mazzarino MC, Gangemi P, Nicotra G, Curatolo S, Massimino D, Plumari A, Merito P, Valente G, et al: Long pentraxin 3: A marker of inflammation in untreated psoriatic patients. Int J Mol Med 18: 415-423, 2006.

19. Wang J, Yang Z, Liu C, Zhao Y and Chen Y: Activated microglia provide a neuroprotective role by balancing glial cell-line derived neurotrophic factor and tumor necrosis factor- $\alpha$ secretion after subacute cerebral ischemia. Int J Mol Med 31: 172-178, 2013.

20. Yilmaz G, Arumugam TV, Stokes KY and Granger DN: Role of T lymphocytes and interferon-gamma in ischemic stroke. Circulation 113: 2105-2112, 2006. International (CC BY-NC-ND 4.0) License. 